\title{
Melatonin inhibits apoptosis and oxidative tissue damage in cisplatin-induced pulmonary toxicity in rats
}

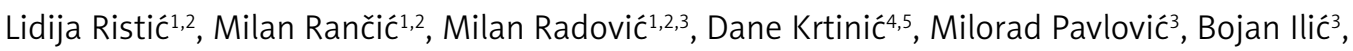

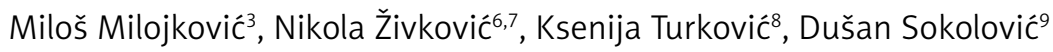

\author{
${ }^{1}$ Department for Internal Medicine, Faculty of Medicine, University of Niš, Niš, Serbia \\ ${ }^{2}$ Clinic for Lung Diseases, Clinical Center Niš, Niš, Serbia \\ ${ }^{3}$ Clinic for Thoracic Surgery, Clinical Center Niš, Niš, Serbia \\ ${ }^{4}$ Department for Pharmacology with Toxicology, Faculty of Medicine, University of Niš, \\ Niš, Serbia \\ ${ }^{5}$ Clinic for Oncology, Clinical Center Niš, Niš, Serbia \\ ${ }^{6}$ Department for Pathology, Faculty of Medicine, University of Niš, Niš, Serbia \\ ${ }^{7}$ Center for Pathology and Pathological Anatomy, Clinical Center Niš, Niš, Serbia \\ ${ }^{8}$ Clinic for Lung Diseases, Clinical Center Kosovska Mitrovica, Kosovska Mitrovica, \\ Serbia \\ ${ }^{9}$ Department of Biochemistry, Faculty of Medicine, University of Niš, Niš, Serbia
}

Submitted: 21 August 2019

Accepted: 13 January 2020

Arch Med Sci

DOI: https://doi.org/10.5114/aoms.2020.95952

Copyright $\odot 2020$ Termedia \& Banach

\begin{abstract}
Introduction: Cisplatin is one of the most frequently used chemotherapeutics, which is known to cause both tumor and normal lung tissue damage through the generation of free radicals and cells apoptosis/necrosis. Melatonin is a neurohormone that regulates numerous physiological processes in the body both through receptor pathways and by maintaining tissue redox homeostasis.

Material and methods: The extent of rat lung damage induced by cisplatin and the effects of melatonin on this process was determined based on the pathohistological changes and biochemical disturbances in tissue lipid peroxidation, protein carbonyl modification and in the activity of xanthine oxidase (XO), caspase-3 and DNases.

Results: Histopathological analysis of rat lung tissue obtained from animals that received cisplatin found them to be edematous, with significant deterioration of alveolar epithelium. These morphological changes are accompanied by a significant increase in all studied oxidative stress-related parameters, as well as with the activity of apoptosis-related enzymes. A five-day treatment with melatonin completely prevented a cisplatin-induced increase in oxidative stress-related parameters and in the activity of XO, caspase-3 and alkaline DNase. Also, the histopathological changes observed during microscopic analysis were much less pronounced than in the group that received cisplatin only.

Conclusions: These results can potentially be connected with the ability of melatonin to inhibit the activity of XO, caspase-3 and alkaline DNase and/ or its ability to scavenge free radicals, thus preventing lung damage induced by cisplatin.
\end{abstract}

Key words: melatonin, cisplatin, lung, apoptosis, xanthine oxidase.

\author{
Corresponding author: \\ Prof. Dušan Sokolović \\ Department of Biochemistry \\ Faculty of Medicine \\ University of Niš \\ Zorana Đinđića 81 \\ 18000 Niš, Serbia \\ Phone: +381642136478 \\ Fax: +38118238770 \\ E-mail:dusantsokolovic@ \\ gmail.com
}




\section{Introduction}

Cisplatin (cis-dichlorodiammine platinum II, CP) is one of the most well-known chemotherapeutic agents, which has been routinely administered to patients with different malignancies, including non-small cell lung carcinoma [1]. By increasing the dose of CP the therapeutic potential of this drug increases, but the risk for the occurrence of various side effects increases as well [2]. Pulmonary fibrosis is one of the main side-effects that arise after the administration of cisplatin, mainly in combination with other chemotherapeutic agents, to patients with different malignancies [3]. Besides significant damage to tumor tissue, CP causes normal lung tissue damage as well. Such damage is known to be associated with chronic obstructive pulmonary disorder and pulmonary dysfunction in humans, which are thought to be direct consequence of the lung tissue oxidative stress (generation of reactive oxygen species (ROS)) and deterioration in antioxidant status [4]. An additional mode of action of $C P$, besides the depletion of tissue antioxidant capacities, involves the activation of caspase(s), and consequential apoptosis, as well as the initiation of necrosis due to abortion of apoptosis [5].

Melatonin (MLT) is a pineal gland hormone whose cyclic secretion is mainly dependent on the light/dark cycle. The activity of MLT is predominantly related to its interaction with melatonin receptor $1 \mathrm{~A}$ (MT1) and melatonin receptor 1B (MT2), of which MT1 receptors are found to be highly expressed in rat lung tissue [6]. Apart from MLT receptor-mediated activity, this neurohormone acts as an antioxidant and is able to maintain tissue redox homeostasis, which is also important for its physiological functions [7]. The antioxidant activity of MLT is connected to numerous mechanisms which include electron and/or hydrogen transfer, radical adduct formation, metal chelation, and the repair of biological targets [7]. Also, there are data suggesting that MLT possesses immunomodulatory, anti-aging and anti-cancer effects, as well as the ability to maintain endothelial integrity and improve blood cell function [8].

Since CP is extensively used for the treatment of lung cancers, our study was designed to determine to what extent the co-application of MLT would prevent lung tissue damage that follows CP administration. The effects of MLT on CP-induced lung tissue damage was measured based on the changes in oxidative-stress related parameters (malondialdehyde and protein carbonylation content), as well as the activity of xanthine oxidase, alkaline and acidic DNase and caspase-3. Additionally, pathohistological analysis of the lung tissue samples obtained from different groups was conducted in order to associate morphological changes with those at the biochemical level.

\section{Material and methods}

\section{Drugs, chemicals, and instruments}

All reagents and solvents used in this investigation were of analytical grade or higher and were obtained from Sigma-Aldrich (St. Louis, MO, USA) or Carl Roth (Karlsruhe, Germany). For each experimental procedure, the reagents were made fresh on the day of the experiment. On the day of the experiment, MLT was dissolved in absolute ethanol and further diluted with a sterile saline solution $(0.9 \% \mathrm{NaCl})$ prior to the intraperitoneal administration at a dose of $50 \mathrm{mg} / \mathrm{kg}$ [9]. Spectrophotometric analyses were performed using a V-1800 Shimadzu spectrophotometer and/or microplate reader (Multiskan Ascent; Labsystems, Helsinki, Finland).

\section{Animals and housing}

Experimental animals were obtained from the Research Centre of the Faculty of Medicine, University of Nis. In total, 24 male Wistar rats (225-275 g) allocated to four identical groups were used in the experiment. Prior to the experiment, the animals were housed in groups under a standard laboratory environment $\left(22 \pm 2^{\circ} \mathrm{C}\right.$, humidity $\left.60 \%\right)$ with a constant $12 / 12 \mathrm{~h}$ light and dark cycles. Food and water were available ad libitum throughout the experiment. All experimental procedures were conducted in compliance with the European Council Directive (EU Directive of 2010; 2010/63/EU) and were approved by the local ethics committee.

\section{Experimental design}

Lung tissue damage induced by CP was performed as described previously [10]. Groups of animals were treated for five days as follows: Group I - Vehicle treated group - received a daily injection of vehicle $1 \mathrm{ml} / \mathrm{kg}$; Group II - MLT treated group - received a daily injection of MLT $(50 \mathrm{mg}$ / kg) for five days; Group III - CP treated group received CP injection $(10 \mathrm{mg} / \mathrm{kg})$ on the $3^{\text {rd }}$ day of the experiment; Group IV - CP and MLT treated group - received MLT for five days (50 mg/kg), and a single injection of CP $(10 \mathrm{mg} / \mathrm{kg})$ on the $3^{\text {rd }}$ day.

Twenty-four hours after the last treatment all animals were sacrificed with an overdose of ketamine (Ketamidor 10\%; Richter Pharma AG, Wels, Austria) and both lungs were removed for tissue biochemical (frozen and stored at $-80^{\circ} \mathrm{C}$ ) and histopathological (fixated in 10\% buffered formalin) analyses.

\section{Tissue homogenate preparation and protein determination}

Tissue samples frozen for biochemical analyses were homogenized in cold distilled water $(10 \%, \mathrm{w} / \mathrm{v})$ and centrifuged $\left(12,000 \mathrm{rpm}, 10 \mathrm{~min}\right.$ at $\left.4^{\circ} \mathrm{C}\right)$ in order 
to obtain a clear supernatant that was further used for the determination of tissue biochemical parameters. The protein content in lung tissue homogenate was determined using Lowry's method [11] and the concentration of proteins was calculated based on the bovine serum albumin standard curve.

\section{Tissue biochemical analyses}

\section{Xanthine oxidase activity determination}

Enzyme activity determination was based on the uric acid production in a reaction of xanthine oxidase $(\mathrm{XO})$ and xanthine $(0.6 \mathrm{mM})$, after incubation at $37^{\circ} \mathrm{C}$ for $30 \mathrm{~min}$. The activity of $X O$ was expressed as $\mathrm{mU} / \mathrm{mg}$ of lung tissue proteins, using a molar coefficient of $7.6 \times 10^{-3} \mathrm{M} / \mathrm{cm}$ [9].

\section{Lipid and protein damage determination}

The amount of lipid peroxidation was estimated through the levels of malondialdehyde (MDA), measured using a spectrophotometrically. The method is based on the MDA reaction with thiobarbituric acid, under increased heat, which form a colored product whose absorbance can be measured at $532 \mathrm{~nm}$ [12]. The concentration of MDA in lung tissue was calculated using a standard curve and the results are expressed as nmol of MDA per mg of tissue proteins.

Protein carbonyl content (PCC) was used for the quantification of oxidatively modified proteins. Their content was determined spectrophotometrically, using 2,4-dinitrophenylhydrazine as a coloring reagent [12]. The concentration of reactive carbonyl derivatives was determined using a molar extinction coefficient for 2,4-dinitrophenylhydrazine at $370 \mathrm{~nm}\left(22 \times 10^{3} \mathrm{l} / \mathrm{mol} / \mathrm{cm}\right)$. The obtained results are expressed as $\mu \mathrm{mol} / \mathrm{mg}$ of lung tissue proteins.

\section{Caspase-3 (Ser29) activity determination}

The amounts of caspase- 3 were determined using an ELISA kit (ab181418) obtained from Abcam, UK. The assay range was $0.156-10 \mathrm{ng} / \mathrm{ml}$ and the obtained data are expressed as $\mathrm{ng} / \mathrm{mg}$ of tissue proteins.

\section{Determination of alkaline and acidic DNase activity}

Alkaline and acidic DNase activities were determined based on previously described methods [13] using calf thymus DNA as a substrate. Alkaline DNase activity was determined at an optimum $\mathrm{pH}$ of 7.4 in Tris- $\mathrm{HCl}$ buffer, while the acidic DNase activity was determined using acetate buffer at an optimum $\mathrm{pH}$ of 5.0. The amount of DNA that remained after the reaction was determined spectrophotometrically at $260 \mathrm{~nm}$ and the enzyme activity was expressed as $U$ per $\mathrm{mg}$ of proteins.

\section{Histopathological analysis}

Tissue samples fixed in formalin were further processed following standard histopathological procedures and at the end, tissue was embedded in paraffine molds. Afterward tissue samples were cut into 4-5 $\mu \mathrm{m}$ thick sections and stained routinely with hematoxylin and eosin (HE) technique. Tissue examinations were performed using a light microscope (Olympus BX43, Olympus Corporation, Tokyo, Japan) and digital photographs were obtained using an imaging system (Olympus cell Sens platform standard, Olympus Corporation, Tokyo, Japan) at $200 \times$ magnification. Evaluated histopathological changes included lung tissue interstitial edema or fibrosis, alveolar damage and presence of hemorrhagic foci. The extent of changes was scored as follows: (-) absent; (+) mild; (++) moderate and (+++) significant, by a pathologist who was blinded to the treatment protocols.

\section{Statistical analysis}

The results obtained from biochemical analyses were presented as mean \pm SD and further compared using one-way ANOVA followed by Tukey's post hoc test. Probability values ( $p$ ) less than or equal to 0.05 were considered to be statistically significant.

\section{Results}

\section{Oxidative damage-related biochemical parameters}

The application of CP (group III and IV) caused a statistically significant increase in lung tissue XO activity compared to the untreated animals (group I, Table I). When MLT was applied together with CP a moderate, still statistically significant reduction compared to the CP-treated group in XO activity was observed (Table I).

The amounts of oxidatively modified lipids (MDA) and proteins (PCC) were found to be statistically significantly increased, compared to group I (untreated animals), in lung tissue of rats injected with CP. In the group of animals injected with MLT and CP (group IV) statistically significantly lower amounts of both measured parameters were found compared to CP-treated rats. The concentrations of these two biomarkers were almost identical to the ones found for control and MLT treated groups of rats since there were no statistically significant differences between these groups (Table I).

\section{Apoptosis-related biochemical parameters}

The caspase- 3 activity was statistically significantly increased, compared to the untreated animals, in the lung tissue of rats treated with CP only (group III) (Figure $1 \mathrm{~A}$ ). The activity of caspase-3 
Table I. Oxidative damage-related biochemical parameters obtained from different experimental groups

\begin{tabular}{|lcccc|}
\hline Parameter/Group & $\begin{array}{c}\text { Group I } \\
\text { Vehicle treated }\end{array}$ & $\begin{array}{c}\text { Group II } \\
\text { MLT treated }\end{array}$ & $\begin{array}{c}\text { Group III } \\
\text { CP treated }\end{array}$ & $\begin{array}{c}\text { Group IV } \\
\text { CP and MLT treated }\end{array}$ \\
\hline XO (mU/mg of proteins) & $0.59 \pm 0.02$ & $0.78 \pm 0.01$ & $1.89 \pm 0.13^{*}$ & $1.14 \pm 0.42^{* *, \#}$ \\
\hline PCC $(\mu \mathrm{mol} / \mathrm{mg}$ of proteins) & $30.5 \pm 8.3$ & $37.2 \pm 3.6$ & $62.5 \pm 9.4^{*}$ & $38.2 \pm 12.5^{\#}$ \\
\hline MDA (nmol/mg of proteins) & $1.56 \pm 0.02$ & $1.50 \pm 0.08$ & $2.78 \pm 0.04^{*}$ & $1.24 \pm 0.76^{\#}$ \\
\hline
\end{tabular}

Data are presented as mean $\pm S D, n=6$; ANOVA, Tukey's post hoc test ${ }^{*} p<0.001 ;{ }^{* *} p<0.01$ vs. Vehicle treated group (Group I); ${ }^{*} p<0.001$ vs. CP treated group.

A
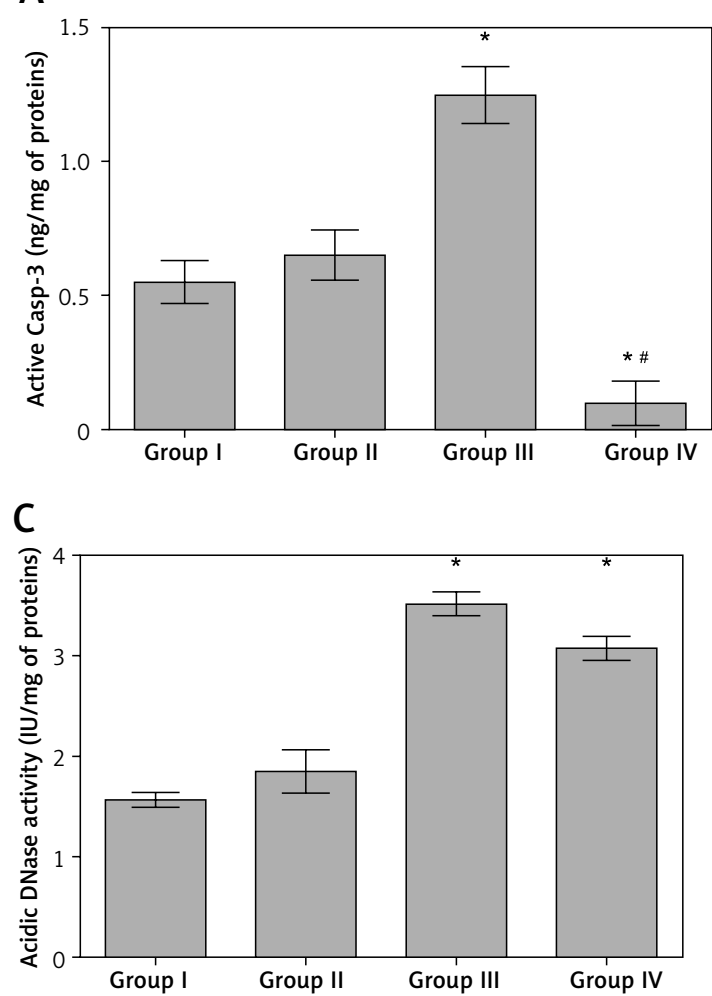

in lungs of rats treated with MLT prior and after $\mathrm{CP}$ injection was found to be significantly lower than those found both in untreated (group I) and CP-treated (group III) rats (Figure $1 \mathrm{~A}$ ).

The activity levels of alkaline and acidic DNase in lung tissue were found to be significantly increased, compared to the untreated or MLT treated rats, by the application of CP (Figure $1 \mathrm{~B}, \mathrm{C}$ ). In the group of animals that received MLT and $\mathrm{CP}$ (group IV) only the activity of alkaline, but not acidic, DNase was found to be significantly decreased, with values far below the ones determined in both CP (group III) and control (group I) rats (Figure $1 \mathrm{~B}, \mathrm{C}$ ).

\section{Histopathological findings}

Examination of lung tissue samples obtained from group I and II revealed normal tissue morphology (score - for all traced parameters in both groups) with distinct alveoli and alveolar septum,

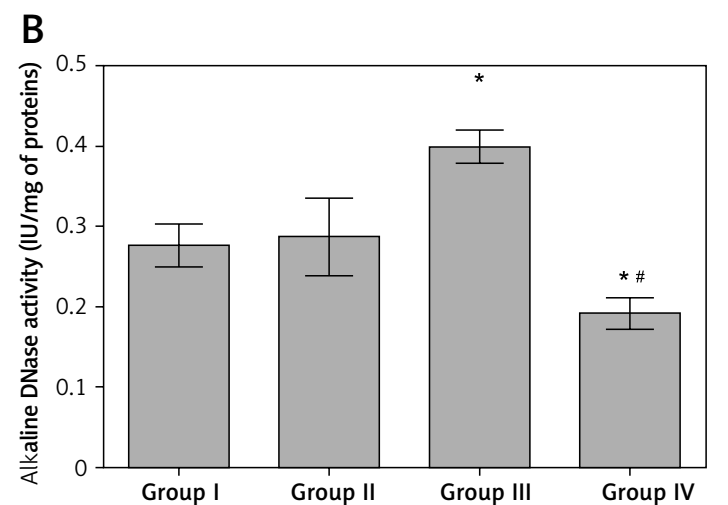

Data are presented as mean value $\pm \mathrm{SD}$; ${ }^{*} p<0.001$ vs. control group (group I), ${ }^{\#} p<0.01$ vs. cisplatin-treated group (group III).

Figure 1. Activity of caspase-3 (A), alkaline (B) and acidic (C) DNase in lung tissue homogenates obtained from different experimental groups

normal shape of Clara cells and of type I and II pneumocytes (Figure 2 A, B, Table II). In group III, animals that received only $C P$, significant changes in tissue morphology, such as interstitial edema and fibrosis, with the disorganized inner epithelium of alveolar bronchioles and hemorrhagic foci, were observed (Figure $2 \mathrm{C}$, Table II). In the group that received MLT prior and after CP injection (group IV) the extent of all previously detected pathological changes was significantly diminished compared to group III (Figure 2 D, Table II).

\section{Discussion}

The activity of $\mathrm{XO}$, an enzyme involved in numerous pathophysiological processes, is generally very complex and its activation/inhibition depends on numerous factors present both within the cell and in the circulation. One thing is sure: the products of its activity, i.e. superoxide ions, nitric oxide directly (part of ROS), cause injury to 
Table II. Pathohistological scores for different experimental groups

\begin{tabular}{|lcccc|}
\hline Parameter/Group & $\begin{array}{c}\text { Group I } \\
\text { Vehicle treated }\end{array}$ & $\begin{array}{c}\text { Group II } \\
\text { MLT treated }\end{array}$ & $\begin{array}{c}\text { Group III } \\
\text { CP treated }\end{array}$ & $\begin{array}{c}\text { Group IV } \\
\text { CP and MLT treated }\end{array}$ \\
\hline Interstitial edema & - & - & ++ & + \\
\hline Interstitial fibrosis & - & - & ++ & + \\
\hline Alveolar damage & - & - & +++ & ++ \\
\hline Hemorrhagic foci & - & - & +++ & ++ \\
\hline
\end{tabular}

Pathohistological score of changes: (-) absent; (+) mild; (++) moderate and (+++) significant.
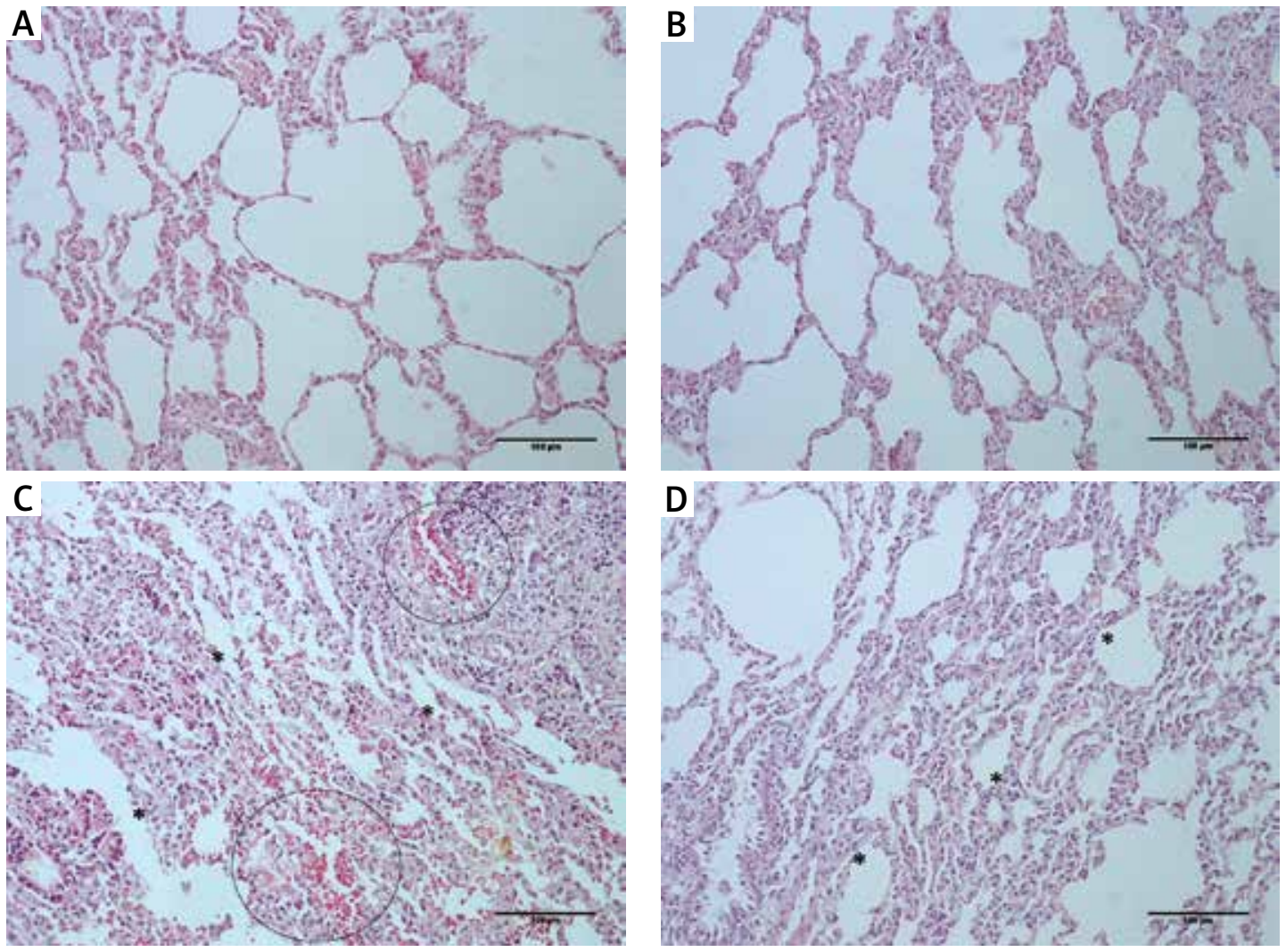

Figure 2. Histological appearance of lung tissue obtained from rats belonging to different experimental groups: (A) control and (B) melatonin treated groups - normal histological structure of lung tissue with clear alveoli, and without any pathological changes; (C) cisplatin-treated group - extensive changes in lung morphology with alveoli epithelium damage (asterisk) and hemorrhagic foci (circled); (D) melatonin and cisplatin-treated group - some degree of alveolar epithelium degeneration (asterisk) but without other significant morphological alterations (HE staining; 200× magnification)

proteins, lipids, and DNA in the vicinity of XO [14]. Also, lung tissue is a target for distant damage by superoxide radicals produced in different $\mathrm{XO}$ expressing tissue. The lung tissue edema, and to some extent cell damage, can be associated with the activity of $\mathrm{XO}$ within the lung tissue, as well as with the produced superoxide radicals [15]. The activity of MLT, which in the present study decreased the CP-induced increase in XO activity, could be attributed to its ability to inhibit the enzyme activity directly and/or to scavenge superoxide radicals that are important for enzyme activity regulation [14].

One of the most prominent processes occurring after excessive ROS production is lipid per- oxidation, which affects all biological membranes (cell and organelle membranes), forming products such as MDA, 4-hydroxynonenal (4-HNE), etc. [16]. Thus, in accordance with previous studies [17], we found the MDA levels to be increased in the lungs of rats injected with CP (Table I). Also, an increase in MDA levels might be partially related to the damage and distortion of pulmonary tissue observed during histopathological analysis (Figure 2 C, Table II). Although MLT did not completely prevent the rise in activity of $\mathrm{XO}$, it fully prevented the formation of MDA in lung tissue, which is in line with the previous findings where a single dose of MLT also prevented MDA formation in carbon tetrachloride damaged rat lung tissue [18]. 
The products of protein carbonylation (PCC), extensively used biomarkers for measuring protein carbonyl accumulation and protein oxidation [19], are found to be increased in lung tissue after CP application (Table I). This biomarker can possibly be used for monitoring acute respiratory distress syndrome since these proteins when present in alveoli cause a disturbance in protease/ antiprotease balance and/or surfactant, or lead to mucus disorganization [20]. The presence of lung edema in CP treated groups of animals (Figure $2 \mathrm{C}$, $\mathrm{D}$, score ++ and + , respectively) might be connected with the formation of PCC and their excretion to alveoli, which then causes water shift to the interstitium. An increase in PCC in lung tissue has been previously proved to be prevented by MLT application [19], which is the case in the present study as well, and it may possibly be correlated with the much better appearance of lung tissue in group IV (Figure 2 D, Table II).

The process of either cell apoptosis or necrosis is highly dependent on the concentration of $C P$, at least under cell culture conditions, [5] and it might be hard to distinguish between the two processes in an in vivo model. An executor caspase, i.e. caspase-3, synthesized as an inactive proenzyme (p32), is initially cleaved by initiator caspase (e.g. caspase-8) and via a further self-catalyzation process forms p17 and p12 active fragments [21]. The activity of active fragments is terminated by the ubiquitin-proteasome system [21], which is in turn found to be inhibited by the products of lipid peroxidation (4-HNE) [22]. Thus, it is not surprising that in the group treated with $\mathrm{CP}$ there is a significant increase in active caspase-3 lung tissue concentrations (Figure $1 \mathrm{~A}$ ), since in the same group the products of lipid peroxidation (MDA levels) are significantly increased as well (Table I). Previous studies found that caspase system activation is closely connected with the extent of lipid peroxidation $[23,24]$ and that the activation of caspase- 3 is directly connected with the microscopical changes occurring in tissue [24]. We found that MLT prevented an increase in caspase- 3 activity, which might be related to its ability to modulate cytochrome $C$ release via the MT1 signaling pathway [25] or by inhibiting the process of lipid peroxidation (Table I). This action of MLT was found to be significantly pronounced since it lowered the activity of caspase- 3 far below the values found in the control group of rats (Figure $1 \mathrm{~A}$ ).

The direct effect of caspase-3, or to be more precise in its active form, is the activation of DNases which further form a scissor-like dimer that breaks the phosphodiester backbone of DNA [26]. Our results showed that both alkaline and acidic DNase activity levels are significantly increased in lung tissue of rats exposed to CP (Figures $1 \mathrm{~B}, \mathrm{C}$ ), which is in line with the pro-apoptotic potential of this chemotherapeutic agent. As previously explained, MLT probably prevents the formation of active caspase-3 via the MT1 mechanism; thus a decrease in DNase activities (in our case only alkaline, Figure 1 B) can be considered a logical result. Similar decreased DNase activities were found in testicular and thymus tissue of animals exposed to microwave radiation $[12,13]$. However, it should be noted that MLT prevented CP-induced increase in caspase- 3 and alkaline DNase activity to values far below the ones measured in the untreated rats (Figures $1 \mathrm{~A}, \mathrm{~B}$ ). Since MLT only prevented an increase in alkaline DNases' activity, a significant alteration in cell morphology (alveolar damage) observed both in the group that received $\mathrm{CP}$ alone (group III) and in the one that received MLT and CP (group IV) (Figures 2 C, D, Table II) might arise from acidic DNase. These results can possibly be connected to the direct damaging effect of CP on the DNA molecule as well [27], which MLT treatment was not able to prevent.

In conclusion, the results obtained here revealed that melatonin prevents lung tissue damage induced by a single injection of cisplatin. This conclusion is based on melatonin's ability to prevent an increase of malondialdehyde and protein carbonylation concentrations, as well as the increase in activity of xanthine oxidase, alkaline and acidic DNase and caspase- 3 induced by cisplatin. The activity of melatonin can be attributed to its potential to inhibit the activity of xanthine oxidase or to scavenge the produced oxygen radicals, as well as to its ability to prevent caspase-3, and consequential DNase activation through the melatonin receptor 1 system that is highly expressed in lung tissue. Such findings suggest that melatonin can be used as supportive therapy in patients receiving cisplatin for the treatment of lung-related carcinomas.

\section{Acknowledgments}

This work was supported by the Ministry of Education, Science and Technological Development of the Republic of Serbia (grant No. III43012).

This work was also funded by the Project of the Faculty of Medicine, University of Niš, Serbia (project Nos. INT-MFN-34 and 37).

\section{Conflict of interest}

The authors declare no conflict of interest.

\section{References}

1. Liu H, Qie P, Yang G, Song Y. miR-181b inhibits chemoresistance in cisplatin-resistant $\mathrm{H} 446$ small cell lung cancer cells by targeting Bcl-2. Arch Med Sci 2018; 14: 745-51.

2. Chen $Y$, Jungsuwadee P, Vore M, Butterfield DA, St Clair DK. Collateral damage in cancer chemotherapy: oxidative stress in nontargeted tissues. Molec Interv 2007; 7: 147-56. 
3. Charpidou AG, Gkiozos I, Tsimpoukis S, et al. Therapy-induced toxicity of the lungs: an overview. Anticancer Res 2009; 29: 631-9.

4. Ismail M, Hossain MF, Tanu AR, Shekhar HU. Effect of Spirulina intervention on oxidative stress, antioxidant status, and lipid profile in chronic obstructive pulmonary disease patients. Biomed Res Int 2015; 2015: 710-7.

5. Sancho-Martínez SM, Piedrafita FJ, Cannata-Andía JB, López-Novoa JM, López-Hernández FJ. Necrotic concentrations of cisplatin activate the apoptotic machinery but inhibit effector caspases and interfere with the execution of apoptosis. Toxicol Sci 2011; 122: 73-85.

6. Ishii H, Tanaka N, Kobayashi M, Kato M, Sakuma Y. Gene structures, biochemical characterization and distribution of rat melatonin receptors. J Physiol Sci 2009; 59: 37-47.

7. Hardeland R. Antioxidative protection by melatonin: multiplicity of mechanisms from radical detoxification to radical avoidance. Endocrine 2005; 27: 119-30.

8. Onk D, Onk OA, Erol HS, et al. Effect of melatonin on antioxidant capacity, inflammation and apoptotic cell death in lung tissue of diabetic rats. Acta Cir Bras 2018; 33: 375-85.

9. Sokolović DT, Lilić L, Milenković $\mathrm{V}$, et al. Effects of melatonin on oxidative stress parameters and pathohistological changes in rat skeletal muscle tissue following carbon tetrachloride application. Saudi Pharm J 2018; 26: 1044-50.

10. Akunna GG, Nwafor J, Egwu OA, et al. Cisplatin-induced ovarian cytotoxicity and the modulating role of aqueous zest extract of Citrus limonium (AZECL) in rat models. Tradit Med Clin Natur 2017; 6: 1-7.

11. Lowry OH, Rosenbrough NJ, Farr AL, Randall RJ. Protein measurement with the folin phenol reagent. J Biol Chem 1951; 193: 265-75.

12. Sokolovic D, Djordjevic B, Kocic G, et al. Melatonin protects rat thymus against oxidative stress caused by exposure to microwaves and modulates proliferation/apoptosis of thymocytes. Gen Physiol Biophys 2013; 32: 79-90.

13. Sokolovic D, Djordjevic B, Kocic G, et al. The effects of melatonin on oxidative stress parameters and dna fragmentation in testicular tissue of rats exposed to microwave radiation. Adv Clin Exp Med 2015; 24: 429-36.

14. Pacher P, Nivorozhkin A, Szabó C. Therapeutic effects of xanthine oxidase inhibitors: renaissance half a century after the discovery of allopurinol. Pharmacol Rev 2006; 58: 87-114.

15. Gurel A, Armutcu F, Hosnuter M, Unalacak M, Kargi E, Altinyazar C. Caffeic acid phenethyl ester improves oxidative organ damage in rat model of thermal trauma. Physiol Res 2004; 53: 675-82.

16. Kisaoglu A, Borekci B, Yapca OE, Bilen H, Suleyman H. Tissue damage and oxidant/antioxidant balance. Eurasian J Med 2013; 45: 47-9.

17. Afsar T, Razak S, Almajwal A, Khan MR. Acacia hydaspica R. Parker ameliorates cisplatin induced oxidative stress, DNA damage and morphological alterations in rat pulmonary tissue. BMC Complement Altern Med 2018; 18: 49.

18. Radovic M, Ristic L, Krtinic D, et al. Melatonin treatment prevents carbon tetrachloride-induced acute lung injury in rats by mitigating tissue antioxidant capacity and inflammatory response. Bratis Med J 2019; 120: 527-31.

19. Waseem M, Tabassum H, Bhardwaj M, Parvez S. Ameliorative efficacy of quercetin against cisplatin-induced mitochondrial dysfunction: Study on isolated rat liver mitochondria. Mol Med Rep 2017; 16: 2939-45.

20. Dalle-Donne I, Rossi R, Giustarini D, Milzani A, Colombo R. Protein carbonyl groups as biomarkers of oxidative stress. Clin Chim Acta 2003; 329: 23-38.

21. Lane D, Côté M, Grondin R, Couture MC, Piché A. Acquired resistance to TRAIL-induced apoptosis in human ovarian cancer cells is conferred by increased turnover of mature caspase-3. Mol Cancer Ther 2006; 5: 509-21.

22. Myung J, Kim KB, Crews CM. The ubiquitin-proteasome pathway and proteasome inhibitors. Med Res Rev 2001; 21: 245-73.

23. Eken M, Ersoy G, Kaygusuz E, et al. Etanercept protects ovarian reserve against ischemia/reperfusion injury in a rat model. Arch Med Sci 2019; 15: 1104-12.

24. Ayala A, Muñoz MF, Argüelles S. Lipid peroxidation: production, metabolism, and signaling mechanisms of malondialdehyde and 4-hydroxy-2-nonenal. Oxid Med Cell Longev 2014; 2014: 360438.

25. Zhang Y, Cook A, Kim J, et al. Melatonin inhibits the caspase-1/cytochrome c/caspase-3 cell death pathway, inhibits MT1 receptor loss and delays disease progression in a mouse model of amyotrophic lateral sclerosis. Neurobiol Dis 2013; 55: 26-35.

26. Larsen BD, Sørensen CS. The caspase-activated DNase: apoptosis and beyond. FEBS I 2017; 284: 1160-70.

27. Geyikoglu F, Isikgoz H, Onalan H, et al. Impact of high-dose oleuropein on cisplatin induced oxidative stress, genotoxicity and pathological changes in rat stomach and lung. J Asian Nat Prod Res 2017; 12: 1214-31. 